\title{
Contagem bacteriana total do leite: relação com a composição centesimal e período do ano no Estado de Goiás
}

\section{Total bacterial count: relationship to milk composition and period of the year in Goiás State, Brazil}

Válter Ferreira Félix Bueno, ${ }^{*}$ Albenones José de Mesquita, ${ }^{* *}$ Antônio Nonato de Oliveira, ${ }^{* *}$ Edmar Soares Nicolau, ${ }^{* \star * *}$ Rodrigo Balduíno Soares Neves****

\begin{abstract}
Resumo
Apesar de estar entre os maiores produtores de leite do país, o estado de Goiás não tem estudos abrangentes e atualizados relativos à qualidade do leite. Objetivou-se com o presente estudo avaliar a relação existente entre a contagem bacteriana total (CBT) e os teores de gordura, proteína, lactose e sólidos totais do leite cru armazenado em tanques de refrigeração por expansão direta de uso individual, no estado de Goiás, além de verificar a influência do período do ano sobre a CBT. Os dados utilizados pertencem ao arquivo de resultados do Laboratório de Qualidade do Leite do Centro de Pesquisa em Alimentos da Escola de Veterinária da Universidade Federal de Goiás. Foram tabulados os dados da CBT e composição centesimal referentes ao período de outubro de 2002 a setembro de 2003. A CBT foi determinada pela citometria de fluxo e a composição centesimal, pela absorção diferencial de ondas infravermelhas. Foram considerados dois períodos distintos no ano: período das chuvas, de novembro a abril, e período das secas, de maio a outubro. Observou-se correlação positiva entre a concentração de proteína e a CBT, enquanto a concentração de lactose apresentou correlação negativa. A precipitação pluviométrica e umidade ambiente apresentaram correlação positiva com o log da CBT, sendo que as maiores médias da CBT ocorreram no período das chuvas.
\end{abstract}

Palavras-chave: contagem bacteriana, qualidade do leite, tanque de expansão.

\begin{abstract}
Abstrat
Milk quality is a crescent concern in Brazil and the Goiás State does not have any current studies on this subject, although it is among the major producers in the country. The aim of this survey was to verify the relationship between total bacterial count (TBCC) and milk composition (fat, protein, lactose and total solids content) and the influence of year period in TBC in Goiás State, Brazil. Data were obtained from October 2002, to September 2003 in the Laboratory of Milk Quality of the Center of Food Research in the Veterinary School of the Federal University of Goiás. TBC was analyzed through flow citometry and milk composition by infrared differential absorption. The year period was divided in two seasons: a rainy season, from November to April, and a dry season, from May to October. Only lactose content decreased as TBC elevated. The environmental humidity and rainfall showed positive and significant correlation to $\log$ of TBC, and the highest averages of TBC occurred in the rainy season.
\end{abstract}

Keywords: bacterial count, milk quality, bulk tank.

\section{Introdução}

O leite possui condições físico-químicas ideais para o crescimento bacteriano. Entre as diversas espécies bacterianas patogênicas e/ou deteriorantes que podem ser encontradas, destacam-se aquelas da família Enterobacteriaceae e dos gêneros Staphylococcus, Streptococcus, Corynebacterium, Pseudomonas, Alcaligenes, Leuconostoc, Bacillus, Lactobacillus e Listeria (Gilmour e Rowe, 1990). A população microbiana total do leite cru varia em acordo com a contaminação inicial, proveniente do interior da glândula, exterior do úbere e tetos, superfícies de equipamentos e com as condições de armazenamento (Bramley e Mckinnon, 1990).

O interior da glândula mamária, exterior do úbere e tetos, e a superfície dos equipamentos e utensílios de ordenha constituem as principais fontes de contaminação (Murphy e Boor, 1998). A temperatura e umidade ambiente afetam o crescimento microbiano e, portanto, podem influenciar a contaminação do leite (Hogan et al., 1988). A água, em virtude

\footnotetext{
* Centro de Pesquisa em Alimentos (CPA), Escola de Veterinária (EV), Universidade Federal de Goiás (UFG). Escola de Veterinária - Centro de Pesquisa em Alimentos, Campus II da UFG, rodovia GO-080 (saída para Nova Veneza). CEP 74001-970, Goiânia-GO. vbueno@vet.ufg.br

** CPA - EV - UFG. mesquita@vet.ufg.br

*** CPA - EV / UFG. nonato@vet.ufg.br

**** CPA - EV / UFG. rena@vet.ufg.br

*****Laboratório de Qualidade do Leite, CPA - EV / UFG. neves@vet.ufg.br
} 
de sua intensa utilização nas atividades de ordenha, pode constituir expressiva fonte de bactérias contaminantes do leite, e assim, causar elevação da contagem bacteriana (Fonseca et al., 1999).

Como a temperatura exerce grande influência na contagem bacteriana, o leite deve ser estocado na propriedade rural com temperatura inferior a $4,5^{\circ} \mathrm{C}$ (Marshall, 1991). No entanto, Bueno et al. (2004) verificaram que em 41,21\% de 859 tanques de refrigeração de leite de uso individual, no estado de Goiás, o leite estava com temperatura superior a $4,0^{\circ} \mathrm{C}$ no momento de captação pelo caminhão. No mesmo estudo verificou-se que em $11,18 \%$ o leite estava com temperatura superior a $7,0^{\circ} \mathrm{C}$ e que a contagem bacteriana total do leite refrigerado e conservado durante 48 horas acima de $7^{\circ} \mathrm{C}$ era significativamente maior do que a do leite refrigerado e conservado em temperaturas inferiores a esse limite.

A quantificação bacteriana do leite cru auxilia na avaliação dos procedimentos de ordenha e armazenamento na propriedade rural e ao mesmo tempo, permite inferir os prováveis efeitos adversos sobre o rendimento industrial e segurança alimentar do leite. A lactose é utilizada por vários gêneros de bactérias e geralmente seu metabolismo leva à produção de ácido lático, o qual em quantidade elevada, pode instabilizar a caseína. Algumas espécies bacterianas, principalmente as psicrotróficas, também produzem lipases e proteases (Fonseca e Santos, 2000). Essas alterações são responsáveis por limitações na utilização da matéria-prima e comprometem as propriedades organolépticas e a vida de prateleira dos produtos lácteos.

A refrigeração do leite na propriedade rural possibilita 0 aumento do tempo de armazenamento após a ordenha até o tratamento térmico na indústria. Nesse período, uma grande quantidade de bactérias psicrotróficas pode-se desenvolver e afetar a composição do leite (Santana et al., 2001). No entanto, não foram encontrados estudos que relacionam a contaminação do leite, nessas condições, com a intensidade da alteração nos componentes principais do leite.

Apesar de o estado de Goiás destacar-se no cenário nacional devido à sua elevada produção de leite, são poucos os dados relativos à qualidade do leite cru. Paralelamente, observa-se crescente reconhecimento da importância da qualidade do leite, tanto por empresas do setor quanto pelos órgãos de regulação e fiscalização. O Ministério da Agricultura, Pecuária e Abastecimento (MAPA) estabeleceu padrões e normas para a produção de leite no país, envolvendo a CBT (Brasil, 2002). As normas estão contidas na Instrução Normativa no 51 (IN 51) e os padrões da CBT serão exigidos a partir de 1/7/2005, nas regiões Sul, Sudeste e Centro-Oeste do país, inicialmente.

Diante do exposto, objetivou-se com o presente estudo avaliar a relação existente entre a CBT e os teores de gordura, proteína, lactose e sólidos totais do leite cru, armazenado em tanques de refrigeração por expansão direta de uso individual no estado de Goiás, além de verificar a influência do período do ano sobre a CBT.

\section{Material e métodos}

Os dados utilizados no presente trabalho pertencem ao arquivo de resultados do Laboratório de Qualidade do Leite do Centro de Pesquisa em Alimentos da Escola de Veterinária da UFG.
Foram reunidos os resultados da CBT e composição centesimal (teores percentuais de gordura, proteína, lactose e sólidos totais) de amostras de leite colhidas em tanques de refrigeração por expansão direta de uso individual, no período de outubro de 2002 a setembro de 2003.

Foram utilizados os resultados de 16.491 amostras analisadas quanto a CBT e composição centesimal. A CBT foi realizada pela citometria de fluxo, utilizando-se o equipamento BactoScan FC (Foss Electric A/S. Hilleröd, Denmark) e a composição centesimal determinada pela absorção diferencial de ondas infravermelhas, utilizando o equipamento Milkoscan 4000 (Foss Electric A/S. Hilleröd, Denmark).

Para avaliar a influência do período do ano sobre a CBT foram considerados dois períodos distintos: período das chuvas e das secas, sendo o período das chuvas equivalente aos meses de novembro a abril, e o das secas aos meses de maio a outubro. A CBT foi transformada em logaritmo de base 10 (log) para realização das análises estatísticas.

Os dados meteorológicos foram obtidos junto à Empresa Brasileira de Pesquisa Agropecuária - Centro Nacional de Pesquisa em Arroz e Feijão (Embrapa-CNPAF), na estação Capivara, localizada em Santo Antônio de Goiás, distante 12 km de Goiânia. Foram consideradas as médias mensais máximas de temperatura e umidade relativa do ar e a precipitação pluviométrica mensal total.

Fez-se a comparação de médias pelo teste $t$ de Student, análise de variância e determinação do coeficiente de correlação linear (r). O nível de confiança estabelecido foi de 95\%. Para avaliar a influência da CBT, variável independente, sobre os teores de gordura, proteína, lactose e sólidos totais, variáveis dependentes, calculou-se o coeficiente de correlação linear (r) entre cada variável independente e as respectivas variáveis dependentes.

Para realização da análise de variância foram considerados cinco intervalos da CBT, estabelecidos de acordo com valores regulatórios, determinados na IN 51 do MAPA (Brasil, 2002): resultados menores ou iguais a $10.000 \mathrm{UFC} / \mathrm{mL}$ (1), de 11.000 a $100.000 \mathrm{UFC} / \mathrm{mL}$ (2), de 101.000 a $750.000 \mathrm{UFC} / \mathrm{mL}$ (3), de 751.000 a 1.000 .000 UFC/mL (4) e acima de 1.000 .000 UFC/ $\mathrm{mL}$ (5). Calculou-se também o coeficiente de correlação linear entre as temperaturas e as médias mensais do log da CBT, entre as umidades relativas do ar e as médias mensais do log da CBT e entre a precipitação pluviométrica total e as médias mensais do log CBT.

\section{Resultados e discussão}

Os percentuais médios de gordura, proteína, lactose e sólidos totais do leite, de acordo com o intervalo da CBT, bem como a variação observada em cada componente, considerando a diferença entre o intervalo 1 (CBT menor ou igual a 10.000 $\mathrm{UFC} / \mathrm{mL}$ ) e o 5 (CBT acima de 1.000.000 UFC/mL), encontramse na Tabela 1. Pode-se observar que, conforme ocorria elevação da contaminação bacteriana, houve redução significativa apenas no teor de lactose. Ao mesmo tempo, ocorreu aumento da concentração de proteína, enquanto os teores de gordura e sólidos totais não apresentaram alterações significativas, considerando os teores médios obtidos nos intervalos 1 e 5. 
Tabela 1: Percentuais médios de gordura, proteína, lactose e sólidos totais do leite, de acordo com diferentes intervalos de CBT em amostras analisadas no período de outubro de 2002 a setembro de 2003, no estado de Goiás $(n=16.491)$

\begin{tabular}{ccccc}
\hline $\begin{array}{c}\text { CBT } \\
(\times 1000 \text { UFC/mL) }\end{array}$ & $\begin{array}{c}\text { Gordura } \\
(\%)^{*}\end{array}$ & $\begin{array}{c}\text { Proteína } \\
(\%)^{*}\end{array}$ & $\begin{array}{c}\text { Lactose } \\
(\%)^{*}\end{array}$ & $\begin{array}{c}\text { Sólidos } \\
\text { Totais }(\%)^{*}\end{array}$ \\
\hline$\leq 10$ & $3,69 \mathrm{a}$ & $3,26 \mathrm{a}$ & $4,56 \mathrm{a}$ & $12,46 \mathrm{a}$ \\
$11-100$ & $3,73 \mathrm{~b}$ & $3,29 \mathrm{~b}$ & $4,55 \mathrm{~b}$ & $12,52 \mathrm{~b}$ \\
$101-750$ & $3,69 \mathrm{a}$ & $3,29 \mathrm{~b}$ & $4,54 \mathrm{c}$ & $12,48 \mathrm{a}$ \\
$751-1.000$ & $3,71 \mathrm{ab}$ & $3,29 \mathrm{~b}$ & $4,53 \mathrm{c}$ & $12,49 \mathrm{ab}$ \\
$>1.000$ & $3,68 \mathrm{a}$ & $3,30 \mathrm{c}$ & $4,54 \mathrm{c}$ & $12,48 \mathrm{a}$ \\
\hline Variação** & $-0,27 \%$ & $+1,23 \%$ & $-0,44 \%$ & $+0,16 \%$ \\
\hline
\end{tabular}

* Letras diferentes na mesma coluna indicam diferença significativa $(\mathrm{P}<0,05)$.

** Considerando as médias do intervalo 1 e 5 .

Os coeficientes de correlação linear ( $r$ ) entre o log da CBT e os valores percentuais de gordura, proteína, lactose e sólidos totais do leite, encontram-se na Tabela 2. Observou-se a ocorrência de correlação significativa entre o log da CBT e os teores de gordura, proteína, lactose e sólidos totais do leite, embora os valores possam ser considerados baixos. No entanto, a análise dos resultados do coeficiente de determinação $\left(\mathrm{r}^{2}\right)$ permite constatar que a variação dos componentes em função da CBT atingiu no máximo 0,16\%, para proteína e lactose, o que pode ser considerado irrelevante. O fato dos coeficientes de correlação serem significativos, apesar de baixos, pode ser devido ao grande número de amostras utilizadas (Sampaio, 1998).

Tabela 2: Correlação linear entre o log da contagem bacteriana total (CBT) e os teores de gordura, proteína, lactose e sólidos totais de 16.491 amostras de leite e entre - log da CBT e a temperatura ambiente, umidade relativa do ar e precipitação pluviométrica no período de outubro de 2002 a setembro de 2003, no estado de Goiás

\begin{tabular}{ccccc}
\hline Componente & $\begin{array}{c}\text { Tipo de } \\
\text { Correlação }\end{array}$ & $r^{1}$ & $P^{* *}$ & $r^{2 * * *}$ \\
\hline Gordura & negativa & 0,03 & $<0,0001$ & 0,0009 \\
Proteína & positiva & 0,04 & $<0,0001$ & 0,0016 \\
Lactose & negativa & 0,04 & $<0,0001$ & 0,0016 \\
Sólidos totais & positiva & 0,02 & 0,0446 & 0,0004 \\
Temperatura $\left({ }^{\circ} \mathrm{C}\right)$ & negativa & 0,30 & 0,3441 & 0,09 \\
Umidade $(\%)$ & positiva & 0,76 & 0,0042 & 0,5776 \\
Precipitação $(\mathrm{mm})$ & positiva & 0,93 & $<0,0001$ & 0,8649 \\
\hline
\end{tabular}

* Coeficiente de correlação linear.

** Probabilidade de cometer erro tipo 1.

*** Coeficiente de determinação (Eberhart et al., 1982).

Apesar de que estudos semelhantes não foram encontrados para dar suporte a uma discussão dos resultados obtidos no presente trabalho, a princípio, em virtude da facilidade de degradação principalmente da lactose (Fonseca e Santos, 2000) e da elevada contaminação de algumas amostras (intervalo 5: acima de 1.000.000 UFC/mL) os percentuais de redução observados podem ser considerados baixos (Tabela 1). Provavelmente a reduzida variação, que se refletiu nos baixos coeficientes de correlação linear (Tabela 2), ocorreu devido ao fato de que o leite estava armazenado em condições de refrigeração, o que diminui a velocidade de crescimento bacteriano (Franco, 1996) e, conseqüentemente, a utilização de nutrientes.

Assim considerando, admite-se que a CBT observada seja decorrente principalmente de elevada contaminação inicial. Para confirmar essa suposição, seria apropriada a realização da CBT em amostras colhidas na sala de ordenha (balança e unidade final), na chegada do leite ao tanque, e no tanque em diferentes intervalos de tempo $(0,12,24,36$ e 48 horas de armazenamento), além da avaliação da temperatura do leite no tanque.

Por outro lado, a concentração de proteína aumentou conforme a CBT aumentou (Tabelas 1 e 2). Considerando que a degradação dos componentes protéicos exige uma grande atividade metabólica dos microrganismos, é provável que tenha ocorrido uma concentração relativa, em virtude da degradação da lactose e gordura, componentes que reduziram com o aumento da CBT. O aumento observado refletiu na concentração de sólidos totais, que manifestou elevação, embora não tenha sido significativa. A confirmação dessa hipótese exige estudos específicos, envolvendo a determinação das espécies bacterianas presentes e a atividade proteolítica em temperatura de refrigeração.

Deve-se considerar também a possibilidade de limitações do método analítico, principalmente em relação à determinação da concentração de proteína e gordura. O princípio utilizado considera as frações protéica e lipídica totais e não discrimina valores de caseína e ácidos graxos livres. Assim, esses componentes poderiam estar reduzidos em virtude da ação de enzimas produzidas por bactérias psicrotróficas, conforme relata Santana et al., 2001 embora sem alteração dos valores de proteína e gordura total.

Portanto, a determinação das concentrações de caseína e ácidos graxos livres, paralelamente ao método utilizado, pode responder a esse questionamento e, conseqüentemente, validar ou não o procedimento utilizado no presente trabalho. Essa resposta é de grande importância aos produtores e às fábricas de laticínios, principalmente quando se considera a possibilidade de implantação de programas de pagamento do leite com base na composição centesimal (Ibarra, 2004).

Os dados meteorológicos e as médias da CBT e log da CBT no período das águas e secas encontram-se na Tabela 3. Pode-se observar que não houve diferença significativa entre as médias da temperatura máxima no período das chuvas e das secas. Em relação à umidade relativa do ar e precipitação pluviométrica, a média do período das chuvas foi significativamente maior que a do período das secas. O log da CBT no período das chuvas foi significativamente maior do que no período das secas. 
Tabela 3 - Dados meteorológicos e médias aritméticas da CBT e log da CBT de acordo com o período do ano, no intervalo de outubro de 2002 a setembro de 2003, no estado de Goiás

\begin{tabular}{|c|c|c|c|c|c|c|c|c|}
\hline \multirow{2}{*}{ Período } & \multicolumn{3}{|c|}{ Dados Meteorológicos } & \multirow{2}{*}{$n^{4}$} & \multicolumn{2}{|c|}{ CBT (x1000 UFC/mL) } & \multicolumn{2}{|c|}{ Log da CBT* } \\
\hline & $\mathrm{T}^{1^{*}}$ & $\mathrm{U}^{2^{*}}$ & $\mathrm{P}^{3^{*}}$ & & Média & $s^{5}$ & Média & $\mathrm{s}^{5}$ \\
\hline Chuvas & $29,3 a$ & $93,5 a$ & $238,7 a$ & 7.199 & 2.690 & 7.213 & $5,44 a$ & 0,93 \\
\hline Secas & $30,7 a$ & $80,5 b$ & $17,4 b$ & 9.292 & 1.640 & 5.686 & $5,16 b$ & 0.89 \\
\hline
\end{tabular}

${ }^{1}$ Média da temperatura máxima $\left({ }^{\circ} \mathrm{C}\right)$.

${ }^{2}$ Média da umidade relativa do ar máxima (\%).

${ }^{3}$ Precipitação pluviométrica total $(\mathrm{mm})$.

${ }^{4}$ Número de amostras no período.

${ }^{5}$ Desvio padrão.

*Letras diferentes na mesma coluna indicam diferença significativa $(P<0,05)$.
$\mathrm{mL}$. Pode-se constatar na Tabela 3 que, independentemente do período do ano, os resultados da CBT estavam acima desses valores.

A ocorrência de resultados elevados pode indicar existência de falhas generalizadas nos procedimentos de ordenha e refrigeração do leite na propriedade (Bramley e Mckinnon, 1990; Marshall, 1991; Murphy e Boor, 1998; Soriano et al., 2001). A suposição de falhas na higiene de ordenha reforça-se pelos resultados obtidos no estado de Goiás por Andrade (1997) e Dias Filho (1997) que constataram procedimentos inadequados por parte dos ordenhadores e comprovaram sua relação com a qualidade do leite. A falta de realização adequada da

Os coeficientes de correlação linear $(r)$ entre o log da CBT e a temperatura, entre o log da CBT e a umidade relativa do ar e entre o log da CBT e a precipitação pluviométrica podem ser vistos na Tabela 2. Pode-se constatar que o log da CBT foi significativamente influenciado pela umidade ambiente e precipitação pluviométrica, sendo que $57,76 \%$ e $86,49 \%$ (coeficiente de determinação), respectivamente, das variações do log da CBT devem-se às variações da umidade ambiente e precipitação pluviométrica. A correlação entre a temperatura ambiente e o log da CBT não foi significativa.

Observa-se na Tabela 3 que a CBT foi significativamente maior no período das chuvas, coincidindo com as diferenças observadas na umidade relativa do ar e na precipitação pluviométrica. O período das chuvas favorece o aumento da contaminação ambiental, o acúmulo de lama nas instalações e maior ocorrência de tetos sujos no momento da ordenha. Esses fatores, associados às falhas na rotina de ordenha, podem ter causado uma elevada contaminação inicial.

Hogan et al. (1988) afirmaram que a CBT é influenciada pela umidade e temperatura ambiente. Observa-se na Tabela 2 que a correlação entre o log da CBT e a temperatura não foi significativa, mas, por outro lado, foi significativa entre a umidade relativa do ar e entre a precipitação pluviométrica total. Pode-se verificar também que $86,49 \%$ das variações na CBT deveram-se às variações na precipitação pluviométrica total. A ausência de correlação significativa com a temperatura ambiente pode ser explicada pelo fato de que o leite não era mantido à temperatura ambiente e também porque não houve diferença significativa na temperatura máxima nos períodos considerados (Tabela 3 ).

Bramley e Mckinnon (1990) afirmaram que CBT acima de 100.000 UFC/mL indica sérias falhas de higiene na produção, enquanto resultados inferiores a $20.000 \mathrm{UFC} / \mathrm{mL}$ refletem boas práticas de higiene. Philpot e Nickerson (2002) afirmaram que todo produtor deve se esforçar para produzir leite com contagem padrão em placas inferior a 10.000 UFC/ limpeza e sanitização do tanque de refrigeração também contribui para o comprometimento da qualidade microbiológica do leite (Mendonça et al., 2001a).

A suposição de falhas na refrigeração do leite é baseada nos resultados de Bueno et al. (2004), os quais verificaram que o leite refrigerado e conservado em temperatura acima de $7^{\circ} \mathrm{C}$ apresentou CBT significativamente maior do que o refrigerado e conservado em temperaturas inferiores a $7^{\circ} \mathrm{C}$. Esses autores constataram também que o leite de $11,18 \%$ dos tanques de expansão de uso individual estava com temperatura acima de $7^{\circ} \mathrm{C}$ no momento da colheita da amostra.

Assim, deve-se investir em medidas de incentivo financeiro, educação e treinamento continuado dos produtores e ordenhadores, a exemplo da recomendação de Van Schaik et al. (2002), com vistas à produção de leite de elevada qualidade (Philpot e Nickerson, 2002). Para tanto, torna-se apropriado a criação e implantação de um programa institucionalizado, com participação dos diferentes segmentos envolvidos na cadeia produtiva.

Dessa forma, a remuneração dos produtores pode ser melhorada através de programas de pagamento por qualidade (Informativo..., 2001). Assim, além de atender às exigências regulamentares (Brasil, 2002), evitar-se-ia a exclusão de produtores do mercado formal, o que poderia acarretar problemas sociais e aumento da comercialização informal de leite e derivados.

\section{Conclusões}

Diante dos resultados obtidos e de acordo com as condições de realização do presente estudo, pode-se concluir que a elevação da CBT causa pequenas alterações nas concentrações de gordura, proteína, lactose e sólidos totais do leite e que, no estado de Goiás, a CBT do leite é maior no período das chuvas.

\section{Agradecimentos}

Ao CNPq, pela bolsa de mestrado do primeiro autor, à equipe do CPA, pelo apoio irrestrito e à Embrapa-CNPAF, pela cessão dos dados meteorológicos. 


\section{Referências}

ANDRADE, M.A. Mastite Bovina Subclínica: prevalência, etiologia e freqüência de patógenos isolados das mãos de ordenhadores e teteiras, e testes de sensibilidade a drogas antimicrobianas. 1997. 113 f. Dissertação (Mestrado em Medicina Veterinária) - Escola de Veterinária - Universidade Federal de Goiás, 1997.

BRAMLEY, A.J.; McKINNON, C.H. The microbiology of raw milk. In: ROBINSON, R.K. Dairy Microbiology: The microbiology of milk. 2. ed. Barking: Elsevier Science Publishers, 1990. p.163-208.

BRASIL. Instrução Normativa no. 51, de 18 de setembro de 2002. Dispõe sobre regulamentos técnicos aplicados ao leite cru e pasteurizado. Diário Oficial da União, 20 set. 2002. Seção 1, n. 183, p. 13-22.

BUENO, V.F.F.; MESQUITA, A.J.; NEVES, R.B.S.; MANSUR, J.R.G.; OLIVEIRA, J.P.; ROSA, A.F.L. Influência da temperatura de armazenamento e do sistema de utilização do tanque de expansão na qualidade microbiológica do leite cru. Revista Higiene Alimentar, v. 18, n. 124, p. 62-67, 2004.

DIAS FILHO, F.C. Perfil do produtor e características das propriedades rurais que utilizam ordenhadeira mecânica na bacia leiteira de Goiânia-GO. 1997. 63 f. Dissertação (Mestrado em Medicina Veterinária) - Escola de Veterinária - Universidade Federal de Goiás, 1997.

EBERHART, R.J.; HUTCHINSON, L.J.; SPENCER, S.B. Relationships of bulk tank somatic cell counts to prevalence of intramammary infection and to indices of herd production. Journal of Food Protection, v. 45, n. 12, p. 1125-1128, 1982.

FONSECA, L.F.L.; PEREIRA, C.C.; CARVALHO, M.P. Qualidade microbiológica do leite. SIMPÓSIO INTERNACIONALSOBREPRODUÇÃO INTENSIVA DE LEITE, 4., 1999, Caxambu. Anais..., 1999. p. 36-43.

FONSECA, L.F.L.; SANTOS, M.V. Qualidade do leite e controle de mastite. São Paulo: Lemos, 2000.

FRANCO, B.D.G.M. Fatores intrínsecos e extrínsecos que controlam o desenvolvimento microbiano nos alimentos. In: FRANCO, B.D.G.M.; LANDGRAF, M. Microbiologia dos alimentos. São Paulo: Atheneu, 1996. p. 13-26.

GILMOUR, A.; ROWE, M.T. Microorganisms associated with milk. In: ROBINSON, R.K. Dairy Microbiology: The microbiology of milk. 2. ed. Barking: Elsevier Science Publishers, 1990, p.37-75.
HOGAN, J.S.; HOBLET, K.H.; SMITH, K.L.; TODHUNTER, D.A.; SCHOENBERGER, P.S.; HUESTON, W.D.; PRITCHARD, D.E.;BOWMAN, G.L.; HEIDER, L.E.; BROCKETT, B.L.; CONRAD, H.R. Bacterial and somatic cell counts in bulk tank milk from nine well managed herds. Journal of Food Protection, v. 51, n. 12, p. 930-934, 1988.

IBARRA, A.A. Sistema de pagamento do leite por qualidade - visão global. In:DÜRR, J.W.; CARVALHO, M.P.; SANTOS, M.V. O compromisso com a qualidade do leite no Brasil. Passo Fundo: Ed. Universitária, 2004. p. 72-86.

INFORMATIVO da Qualidade. Belo Horizonte: Itambé, a. 1, n. 1, p. 23. 2001.

MARSHALL, J. Differential diagnosis of high TBC. In Practice, v. 13, n. 5, p. 198-201, 1991.

MENDONÇA, A.H.; SOUZA, M.R.; CERQUEIRA, M.M.O.P.; PENNA, C.F.A.M.; CAMARGOS, C.R.M. Estudo de fatores que influenciam a qualidade do leite cru, submetido à coleta a granel. Revista do Instituto de Laticínios "Cândido Tostes", v. 56, n. 321, p. 289-293, 2001.

MURPHY, S.C.;BOOR, K.J. Raw milk bacteria tests and elevated bacteria counts on the farm: a review. PANAMERICAN CONGRESS ON MASTITIS CONTROL AND MILK QUALITY, 1998, Merida. Proceedings..., 1998. p. 232-235.

PHILPOT, N.W.; NICKERSON, S.C. Vencendo a luta contra a mastite. Piracicaba: Westfalia Surge/Westfalia Landtechnik do Brasil, 2002.

SAMPAIO, I.B.M. Estatística aplicada à experimentação animal. Belo Horizonte: Fundação de Ensino e Pesquisa em Medicina Veterinária e Zootecnia, 1998.

SANTANA, E.H.W.; BELOTI, V.; BARROS, M.A.F. Microrganismos psicrotróficos em leite. Higiene Alimentar, v. 15, n. 88, p. 27-33, 2001. SORIANO, C.; MICHEO, C.; MENDIEIRA, V.A.; TABERA, A.; STEFANO, A.; CASASNOVAS, G.; PURRÁN, P.; CORRADETTI, A.; CARABAJAL, $\mathrm{S}$. Evaluación de la calidad de leche de tanque de tambos de la Cuenca Mar y Sierras. Veterinaria Argentina, v. 18, n. 179, p. 654-667, 2001. VAN SCHAIK, G.; LOTEM, M.; SCHUKKEN, Y.H. Trends in somatic cell counts, bacterial counts, and antibiotic residue violations in New York State during 1999-2000. Journal of Dairy Science, v. 85, n. 4, p. 782789, 2002. 